\title{
Chapter 13 \\ Far Beyond the Gay Village: LGBTQ \\ Urbanism and Generation in Montréal's \\ Mile End
}

\author{
Julie A. Podmore
}

\begin{abstract}
Research on LGBTQ neighbourhood formation in the urban West suggests that new patterns of community and identity are reshaping the queer inner-city and its geographies. As gay village districts "decline" or are "de-gayed" and new generations "dis-identify" with the urban ideals that once informed their production, LGBTQ subcultures are producing varied alternatives in other inner-city neighbourhoods. Beyond the contours of ethno-racialization and social class, generational interpretations of LGBTQ urbanism - subcultural ideals regarding the relationship between sexual and gender identity and its expression in urban space-are central to the production of such new inner-city LGBTQ subcultural sites. This chapter provides a qualitative case study Montréal's of Mile End, an inner-city neighbourhood that, by the early 2010s, was touted as the centre of the city's emerging queer subculture. Drawing on a sample of young-adult (22 to 30 years) LGBTQ-identified Mile Enders $(n=40)$, it examines generational shifts in perceptions of sexual and gender identity, queer community and neighbourhoods. The chapter concludes with a discussion of the implications of queer Mile End for theorizing the contemporary queer inner-city.
\end{abstract}

Keywords Montréal • Quebec • Canada • Generations • Generational change • LGBTQ identity $\cdot$ Gay neighborhoods

\subsection{Introduction}

In 2011, the Montréal mainstream media began announcing changes to local LGBTQ (lesbian, gay, bisexual, trans and queer) geographies. One headline read, "The gay and lesbian community is no longer confined to the gay village” (Bélisle 2011) (author's translation). According to the article, Montréal was exhibiting "a new openness" to LGBTQ visibility, proof of which was an increase in small rainbow flags appearing in the windows of businesses throughout the metropolitan area. Signs of an LGBTQ

J. A. Podmore ( $\square)$

Geosciences, John Abbott College, Sainte-Anne-de-Bellevue, QC, Canada

e-mail: Julie.Podmore@johnabbott.qc.ca

Geography, Planning and Environment, Concordia University, Montréal, QC, Canada

(C) The Author(s) 2021

A. Bitterman and D. B. Hess (eds.), The Life and Afterlife of Gay Neighborhoods,

The Urban Book Series, https://doi.org/10.1007/978-3-030-66073-4_13 
presence were especially notable in Mile End, an inner-city neighbourhood undergoing culture-led development, gentrification and increased "place-making" by a new generation of queer-identified young adults (Fig. 13.1). "Queer Mile End" began to receive media coverage and was promoted as the city's new queer neighbourhood. The national LGBTQ publication Xtra! titled an article on Mile End "Out of the Montréal Village and into the world" (McCarthy 2011) suggesting that it represented the liberation of LGBTQ populations from the sexual "ghetto" of the city's gay village [the Village]. But the press also implied that there was an important difference between the queer Mile End subculture and the more mainstream LGBTQ space of the Village. The lesbian publication Entre elles pronounced "The Mile End, the heart of queer life" (Giraud 2011) (author's translation). The press further linked Mile

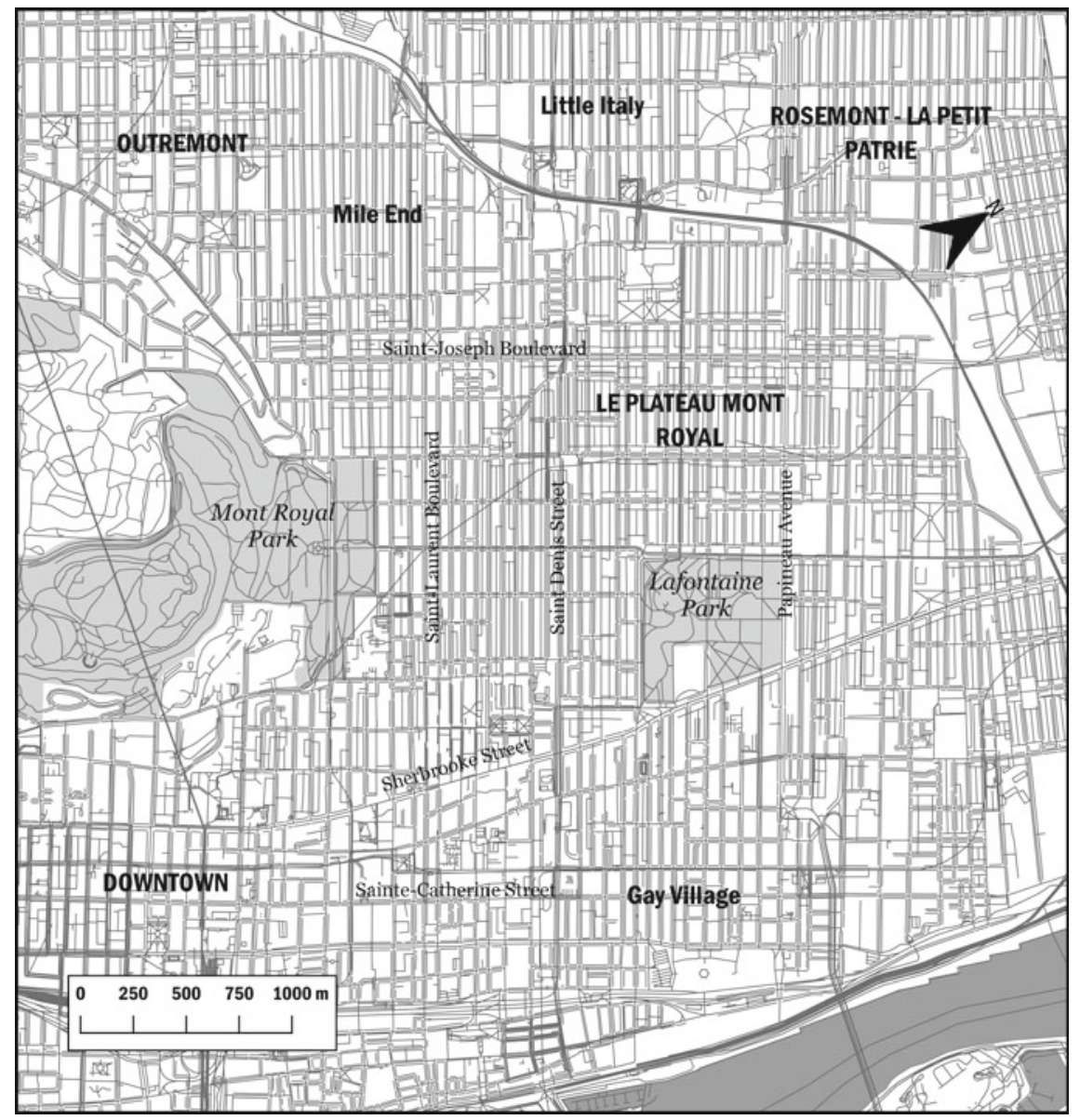

Fig. 13.1 Map of Mile-End and other eastern inner-city Montreal neighbourhoods (Source Map by Author) 
End's young queer subculture to its well-established reputation for hipsters, foodie restaurants and the city's alternative music scene. Xtra!, for example, proclaimed that Mile End distinctively combined "a dash of gay and hip" (Wallberg 2012).

The emergence of new and alternate LGBTQ inner-city neighbourhoods that queer Mile End represents is not unique. From Paris to Sydney, research over the past decades shows a decline, de-gaying, displacement and disidentification with gay villages throughout the urban West (Brown 2014; Collins 2004; Collins and Drinkwater 2017; Doan and Higgins 2011; Ghaziani 2014; Giraud 2014; GormanMurray and Nash 2017; Nash and Gorman-Murray 2014; Ruting 2008). A corresponding decentralization of same-sex households to other inner-city and towards suburban areas is increasingly demonstrated by macro-scale studies (Compton and Baumle 2012; Goldie 2018; Forrest et al. 2019; Hayslett and Kane 2011; Smart and Whittemore 2017; Spring 2013). As Ghaziani (2019: 7) proposes, today's LGBTQ urban geographies form "cultural archipelagos," interconnected "clusters for specific subgroups" in more peripheral inner-city and inner-suburban areas. Qualitative case studies detail the varied places in the LGBTQ urban archipelago through the place-based specificities of outer boroughs such as New York City's Queens or Brooklyn (Gieseking 2016; Martinez 2015), Sydney, Australia's New Town inner suburb (Gorman-Murray and Waitt 2009) and alternative inner-city areas such as London, England's “cosmopolitan post-gay Spitalfields” (Brown 2006), or in Toronto, Canada's Parkdale neighbourhood (Nash 2013a, b). Gorman-Murray and Waitt (2009) characterize such alternatives to the gay village as "queer-friendly" neighbourhoods, areas where a queer presence, while not dominant, is apparent and welcome. Akin to Brown-Saracino's (2011: 361) “ambient community," such neighbourhoods provide a sense of "belonging and connection" shaped through interactions "among heterogeneous proximate individuals" that share similar dispositions, tastes and activities across sexual differences.

This chapter extends this literature through a case study of Montréal's queer Mile End from the perspective of the LGBTQ young adults that shaped and participated in its subculture in the 2010s. Drawing on interviews with young LGBTQ-identified adults (under 30 years of age) $(n=40)$ who lived in Mile End and adjacent neighbourhoods in 2013, it examines the building of a distinctively queer generational habitus within Montréal's inner-city. It is argued that queer subcultural districts such as Mile End represent a spatial shift far beyond the gay village: less a diffuse dispersal of LGBTQ residents from gay villages, they are formed through a generational rejection of established versions of LGBTQ urbanism - subcultural ideals regarding the relationship between sexual and gender identity and its expression in urban space. These generational shifts in understandings of LGBTQ identity, community and neighbourhood potentially offer insight into the greying of gay villages (Bitterman and Hess 2016) as some young adult subcultures "disidentify" with gay village spaces and explicitly create and promote alternatives (Nash 2013a, b). Mile End's young, queer-identified subculture reproduces a distinct queer habitus, a set of class-based dispositions that shape aesthetic ideals and afford cultural capital (Bourdieu 1991). Applied to urbanism, this habitus rejects the rainbow flag commercial visibility and 
gender binary definitions of sexuality in the gay village while promoting a subterranean queer ideal that values anti-normative gender and sexual identities, community inclusion and urban diversity. The chapter's conclusion reflects on the specificities of queer Mile End's class, age and linguistic formulation, and considers the insights that this LGBTQ cluster offers to the study of queer-friendly neighbourhoods.

\subsection{Methodology}

The research profiled in this chapter is drawn from a larger project on Queer Mile End that used snowball sampling and in-depth qualitative interviewing to access and understand the subculture's perceptions and experiences (Atkinson and Flint 2001). The interviews were conducted by a team of four LGBTQ-identified graduate students (two trans-men, one queer woman and one gay man) who developed the sample through their personal networks. The interviews were conducted in 2013 when the student researchers were between 23 and 32 years of age and either living in or frequenting the queer spaces in Mile End. Due to their involvement with the queer Mile End subculture, they were enlisted to define the neighbourhood and develop the questionnaire. Forty qualitative interviews of approximately one hour in length were conducted and transcribed. Participants also completed a socio-demographic profile self-identifying their sexual, gender, ethnic, racial, linguistic and social-class affiliations as well as their regional and national origins. The interviews addressed their identities, migration trajectories and neighbourhood histories; perceptions of other LGBTQ generations, Montréal LGBTQ scenes and neighbourhoods; and experiences of the gay village and Mile End neighbourhoods. Participants were asked to describe Mile End, its queer scene and spaces, and to discuss its queer-friendly characteristics.

Snowball sampling mitigated problems of recruiting a younger "hidden" subculture for the primary researcher (aged 47 years in 2013) (Browne 2005), but the "double insider status" of the field researchers produced a remarkably homogeneous sample (Adriansen and Madsen 2009) in terms of social class, language, "race", occupation and nationality. The age range of the sample was between 22 and 30 years with an average of 26.2 years. Most participants identified as white $(70.0 \%)$, raised in middle/upper-middle-class households $(57.5 \%)$ elsewhere within Canada $(60.0 \%)$, speaking English as their primary language $(90.0 \%)$ and attending university or having recently completed a university degree $(90.0 \%)$. The sample was more heterogeneous in its sexual and gender identities, ethnicities and geographical origins. Only $22.5 \%$ were raised in Montréal, the majority having migrated from cities and towns across Canada $(50.0 \%)$. Within the parameters of contemporary queer subcultures, their definitions of gender and sexual identity were wide-ranging. The next two sections analyze queer identity and urbanism from the perspective of young Mile Enders beginning with an exploration of their sexual and gender identities followed by perceptions of Montréal's gay village and Mile End neighbourhoods. 


\subsection{Generation Queer}

Queer cultural and LGBTQ youth studies note generational shifts in LGBTQ identity and youthful innovation and fluidity regarding gender and sexual identities (Driver 2008; Halberstam 2003; Plummer 2010). Regardless of how they personally identified, Queer Mile Enders were aware of queer politics which had reemerged in Montréal in the early 2000s (Hogan 2005) and was linguistically imported into French around 2010 (Laprade 2014). The profile data revealed the participants' distinct patterns of the gender and sexual identities (Table 13.1). In terms of gender, the largest group identified as "women" or "female" (47.5\%) followed by "men" or "male" (37.5\%), "genderqueer" (androgynous, genderqueer, neutral or non-binary) $(12.5 \%)$ and trans (trans, transgender and transsexual) $(2.5 \%)$. In terms of sexuality, the majority identified as queer $(57.5 \%)$ while the rest were divided between those who exclusively identified as lesbian, gay or bisexual (22.5\%) and those who identified as "queer" and lesbian, gay or bisexual (17.5\%). When cross tabulated, these statistics revealed that those who identified as "women", "genderqueer" or "trans" were the most likely to identify sexually as "queer"; those identifying as men were less likely to identify with queer (53.3\% did not) primarily choosing a gender binary sexual identities such as gay, MSM (men who have sex with men but do not identify as gay) or bisexual.

This gender difference in sexual identity was also reflected in the qualitative interviews. Few participants who identified as gay men also identified as queer $(33.3 \%)$ while a majority of those who identified as women, described their sexuality as "queer" (73.9\%). However, as this quote from Ève reveals, the links between gender and sexuality for women-identified participants were complex:

Table 13.1 Self-identified categories of sexual orientation and gender identity

\begin{tabular}{|c|c|c|c|c|c|}
\hline & $\begin{array}{l}\text { Woman, } \\
\text { Female, } \\
\text { Feminine }\end{array}$ & $\begin{array}{l}\text { Man, Male, } \\
\text { Masculine }\end{array}$ & $\begin{array}{l}\text { Trans, } \\
\text { Transgender, } \\
\text { Transsexual }\end{array}$ & $\begin{array}{l}\text { Androgynous, } \\
\text { Genderqueer, } \\
\text { Neutral }\end{array}$ & Total \\
\hline $\begin{array}{l}\text { Exclusively } \\
\text { queer }\end{array}$ & $\begin{array}{l}17 \\
89.5 \% \\
73.9 \% \\
\end{array}$ & $\begin{array}{l}1 \\
6.7 \% \\
4.3 \% \\
\end{array}$ & $\begin{array}{l}1 \\
100.0 \% \\
4.3 \% \\
\end{array}$ & $\begin{array}{l}4 \\
80.0 \% \\
17.4 \% \\
\end{array}$ & $\begin{array}{l}23 \\
(57.5 \%) \\
100.0 \%\end{array}$ \\
\hline $\begin{array}{l}\text { Exclusively lesbian, } \\
\text { gay or bisexual }\end{array}$ & $\begin{array}{l}1 \\
5.2 \% \\
11.1 \% \\
\end{array}$ & $\begin{array}{l}8 \\
53.3 \% \\
88.9 \% \\
\end{array}$ & $\begin{array}{l}0 \\
0.0 \% \\
0.0 \% \\
\end{array}$ & $\begin{array}{l}0 \\
0.0 \% \\
0.0 \% \\
\end{array}$ & $\begin{array}{l}9(22.5 \%) \\
100.0 \%\end{array}$ \\
\hline $\begin{array}{l}\text { Queer and lesbian, } \\
\text { gay or bisexual }\end{array}$ & $\begin{array}{l}1 \\
5.2 \% \\
14.2 \% \\
\end{array}$ & $\begin{array}{l}5 \\
33.3 \% \\
71.4 \% \\
\end{array}$ & $\begin{array}{l}0 \\
0.0 \% \\
0.0 \%\end{array}$ & $\begin{array}{l}1 \\
20.0 \% \\
14.3 \% \\
\end{array}$ & $\begin{array}{l}7(17.5 \%) \\
100.0 \%\end{array}$ \\
\hline Questioning & $\begin{array}{l}0 \\
0.0 \% \\
0.0 \%\end{array}$ & $\begin{array}{l}1 \\
6.7 \% \\
100.0 \%\end{array}$ & $\begin{array}{l}0 \\
0.0 \% \\
0.0 \%\end{array}$ & $\begin{array}{l}0 \\
0.0 \% \\
0.0 \%\end{array}$ & $\begin{array}{l}1(2.5 \%) \\
100.0 \%\end{array}$ \\
\hline Total & $\begin{array}{l}19(47.5 \%) \\
100.0 \%\end{array}$ & $\begin{array}{l}15(37.5 \%) \\
100.0 \%\end{array}$ & $\begin{array}{l}1(2.5 \%) \\
100.0 \%\end{array}$ & $\begin{array}{l}5(12.5 \%) \\
100.0 \%\end{array}$ & $\begin{array}{l}40 \\
(100.0 \%)\end{array}$ \\
\hline
\end{tabular}


Well, a woman because it is my sex and that is completely fine with me. A lesbian. I would say queer, but right now, I don't feel like I'm part of the queer community in Montréal because the queer community around me is more Anglophone and sometimes I feel like I don't really connect with queer Anglophones. I sometimes feel like I'm not included like I do with other lesbians that I know who are Francophones. They might say that they are queer too, but I feel more like a lesbian, but not like the lesbians in the Village who like to play hockey. I don't feel like I connect with them either. I would say I am between queer and lesbian. (Ève, Francophone, woman, queer/lesbian, 26 years)

As this quotation illustrates, the idea of "queer" identity is strongly associated by Francophones (78.4\% of the Montréal population in 2016) with Anglo-American LGBTQ culture. Moreover, Ève describes a binary between sexual identity, language and urban space where the Mile End is the domain of young queer Anglophones and the Village is the territory of older Francophone gays and lesbians.

Since queer was such an important form of identification, participants were asked what it means to them. Many said that they identified with its power to contest heteropatriarchal norms. For Rudy, queer permits the integration of diverse sexual practices (including polyamory and pansexuality) with gender diversity (such as genderqueer or non-binary), but its power also lies in its opposition to norms: "Well, I feel like my sexuality can generally be described in opposition to hetero-dominant norms" (Rudy, Anglophone, genderqueer, queer, 30 years). Savannah made a similar argument regarding why she identifies as queer:

Queer signifies for me my own relationship with my gender identity which is more fluid than those I know who aren't queer. So, I think that my identity as queer is in some ways a form of alterity. (Savannah, Anglophone/Francophone, woman, queer, 22 years)

A desire for a term representing a more fluid sexual identity was another reason given for identifying with queer rather than lesbian or gay. This was particularly the case for those who also identified as women. The power of queer's fluidity was evident in Jo's reflections on her public identity presentation:

I say I am a lesbian to people because that's what they know of sexuality. Either you are a straight or a gay. So, to them, I'm gay, but I don't identify as gay. I identify as queer, where my sexuality is constantly in rethink. (Jo, Francophone, woman, queer, 30 years)

The second major reason for choosing queer was its inclusivity of varied gender identities. Mer said: “ “.. for the last 13/12 years of my life I identified as a lesbian/gay, but for the last couple of years... I'd love to say I am a queer because I feel it's a more inclusive term" (Mer, Francophone, woman, queer/lesbian, 30 years). In contrast, the category lesbian was especially unpopular (only chosen by 10.4\%) because it was perceived as creating essentialist boundaries of gender around sexuality, producing exclusions for trans people, but also for those who practiced polyamory, or who identified as genderqueer or pansexual.

Many participants distinguished between queer and gay and lesbian identities in intergenerational terms. When asked how their generation differs from previous ones, many said that older generations do not understand nor identify with the word queer: 
Older people don't even know the word queer. Well, they know what queer means, but they don't know. They'd rather call themselves gay, you know, bisexual, lesbian... Some of them do have a lot of queer politics, but don't have the words for it. (Rue, Anglophone, man, queer, 25 years)

Older LGBTQs were depicted not only as being more comfortable with binary configurations of gender, but also as being more invested in these categories to define themselves (i.e. as gays and lesbians or as trans-men and -women). Horatio echoed this sentiment regarding older trans women:

There's a lot of older trans women I know ..., they have different idea of gender than I do and it's kind of a clash ... they're very into like if you're a boy or girl and for them being a woman is really important and good for them. But for me I don't really identify that way. (Horatio, Anglophone, transfeminine, queer, 28 years)

Alexandra represented these differences regarding gender identity as a specific change initiated by her generation and even associates them with progress:

The main thing for me seems to be, just that we're advancing more on gender stuff. So, it's both being more committed to being inclusive on trans issues and like, people who aren't trans being aware of the issues or trying to be allies and stuff. And also, femme visibility is coming up too. So, that's again around gender presentation. Yeah, just like less binary, I think it's getting less binary all the time. That's really nice. (Alexandra, Anglophone, woman, queer, 25 years)

\subsection{Divergent LGBTQ Urbanisms}

The queer Mile End subculture defines itself through several interpretations of gender and sexual identity including anti-normativity, sexual fluidity and non-binary gender. It is also produced through generational contrasts with its predecessors. This section compares queer Mile Enders' perceptions of the gay village and Mile End to further understand how this generational subculture is constructed relationally in urban space by opposing two types of LGBTQ urbanism: (1) the fixed, gender-bound and visible identities in the Village; and (2) the fluid and secondary sexual and gender identities that are celebrated within the framework of neighbourhood diversity in Mile End. While the questionnaire had many lines of inquiry regarding each neighbourhood, the focus here is on responses regarding the identities associated with each neighbourhood and the comparison of their meanings for LGBTQ identity, community and spaces in Montréal.

\subsubsection{The Gay Village}

Montréal's gay village lies on the eastern edge of Montréal's downtown core. It began to develop as both a gayborhood in the early 1980s and, by the mid-1990s, was promoted as such by various levels of government and the media (Hinrichs 
2011). Its business improvement association has also played an important role in promoting and branding the area with decorations such as the pink balls that hang over its pedestrianized main street every summer (Podmore 2015) (Fig. 13.2). The most "visible" LGBTQ space in the city, the Village was a common point of reference for all participants whether they were describing their own residential histories or intergenerational differences in the meaning of queer. However, the questionnaire did have specific questions about perceptions and experiences of the Village. These questions included how often, when and why participants frequented it, what they liked and did not like about it, and who it was for. It is worth noting that most participants reported that they "rarely" frequented the Village. Many also saw it as a space from their past, a place they frequented when they were young or had first arrived in Montréal. It was also associated with "coming-out" and early quests for LGBTQ community.

Important themes emerged in response to the question "who is the gay village for?" First, the participants unanimously identified it as a place for gay men. As Alexandra observed: "Well, the Village seems to me to be pretty obviously centred around gay cis-men... there are just a lot of stores and a lot of the bars and everything. It's very obviously catered to that market" (Alexandra, Anglophone, woman, queer, 25 years). Second, participants associated the village with older generations. Kyle said: "I think it is for the older generation, I think that's who keeps it going. Older generations, 40s and 50s, that's the backbone of the Village, not the young generation" (Kyle, Anglophone, man, gay, 29 years). Third, most said that the Village was for gender binary people. As Marie-Claire observed, the Village belongs to “... people

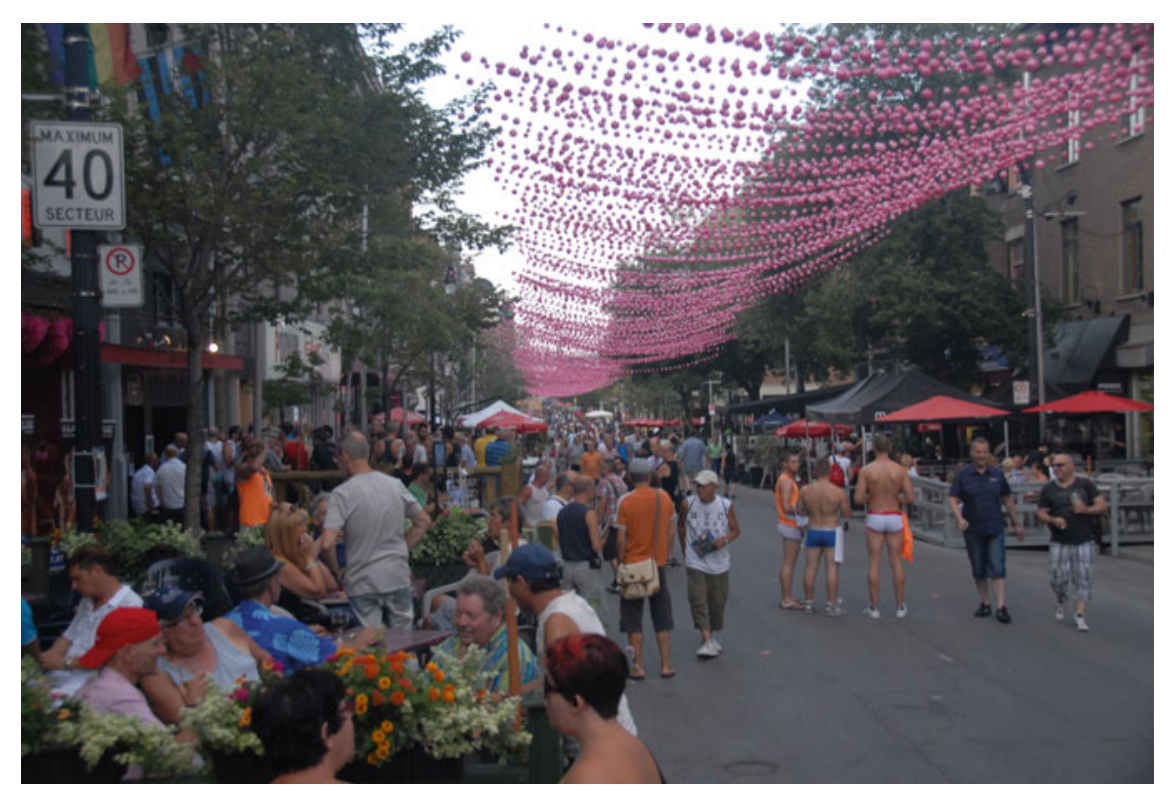

Fig. 13.2 Festivalization and pedestrianization of Montreal's gay village (Source Image by Author) 
who identify as gay, female or male, people who identify as being "born this way"" (Marie-Claire, Francophone, woman, queer/lesbian, 30 years). Rue also made the distinction between queers and gays and lesbians in the Village: “... the Village is not for queer people. The Village is for gays and lesbians" (Rue, Anglophone, man, queer, 25 years).

The Village was primarily seen as a site of homonormativity due to its whiteness, police surveillance, commercialism and tourism. Homonormativity refers to the assimilation of LGBTQ people into mainstream heterosexual society and the promotion of a depoliticized LGBTQ culture that is anchored in consumption (Duggan 2002). The following comments from three of the participants represent this interpretation of the Village:

It just seems like it's just a very different scene. I just have this image of being sort of like either lesbians or gay men which is neither of the things that I identify as. It seems really more commercialized... It seems sort of like the epitome of what white gay capitalist culture is. (Tabatha, allophone, woman, queer, 28 years)

I mean, I guess there's kind of like a dominant gay male culture that dominates that space. That's kind of my sense of it. It's like a mainstream gay culture that is kind of ubiquitous in at least Canada and the States and various other places. It's just it's a certain kind of mainstream. It's like if gay culture could be mainstream. It's like this particular brand of gay male culture that I find very normative in many ways. (Theo, Anglophone, man, queer/gay, 23 years)

I feel like the Village is friendly to a specific type of queer. Not only to a specific type of queer, but a person who wouldn't be as active or supportive of the queer movement. The most predominant or visible members, or successful members of joining the hetero majority, of being accepted by the hetero majority, is the Village. (Zachary, Anglophone, man, gay, 25 years)

Village homonormativity did not simply lead to disidentification but was further underscored by a sense of exclusion. Indeed, the Village was often described as an unwelcoming place for those that queer cultures perceive themselves as working to include such as trans and genderqueer people, young queers and queers of colour. For Rue, it was not only that the Village was primarily made in the image of gay men, but also that “... for female-identified people, like bars, I don't know, it's just not very welcoming, you know? Like, definitely not very welcoming for trans people, definitely not very welcoming for people who just like don't fit in any sort of gender box" (Rue, Anglophone, man, queer, 25 years). Confirming earlier work by Doan (2007), trans participants voiced mixed feelings about the Village. Although it houses many trans community support and activist groups, participants expressed a sense of exclusion and even feelings of hatred from gay men in the Village. For example, Robin described it as a transphobic space:

As a trans-woman, I don't like the Village that much... the only people who actually would call me tranny or would feel like totally fine doing that would be like gay men in the Village, and they would like shout it, you know? Whereas, ... even for like transphobic dudes on the streets, they wouldn't think to call me that necessarily. (Robin, Anglophone, woman, queer, 28 years)

A sense of exclusion also stemmed from its commercialism and the ways that the police survey its public spaces. Young, queer and alternative in appearance, queer 
Mile Enders are not a key clientele targeted by gay village entrepreneurs. Jean said: "I'm just not welcomed there as someone who's not a tourist and as someone who looks probably more like the homeless kids than like the rich suits who want to like go to the bathhouses, you know?" (Jean, Anglophone, genderqueer, queer, 26 years). Queer women, on the other hand, were ambivalent about the Village's commercialism. They often said that there was nothing there to attract them because the target market was gay men. While many went there occasionally, they noted that the Village's social order, revolving around hook ups and saunas, excluded anyone who was not a cis-gendered gay man.

As Village outsiders, participants also saw this area as lacking a sense of community and being rather too commercial and tourist oriented. Village commodification of LGBTQ identities contrasted with the queer urban ideals that oppose commercialism and value community-based productions of space. Thus, the Village was contrasted with the more communal productions of queer spaces in Mile End. For example, Rue said that the Village is "... kind of focused around money and less so on community". Comparing it to Mile End, he said that he would be surprised if there was a pay-as-you-can or fundraiser event in the Village and drew the following conclusion:

That area's not about community and that's like what I would definitely associate as a big component of what queerness, in its political aspect, means to me is community, and that's why I never go down there because to me it's like, you know, exactly what I said, it's like a bunch of ignorant straight cis people that just happen to have gay sex. (Rue, Anglophone, man, queer, 25 years)

The tourist orientation of the Village was also repelled queer Mile Enders. "Tourists"-LGBTQ tourists from elsewhere and non-LGBTQ consumers both local and visiting —-were considered integral to the Village's commodification of LGBTQ identities. Savannah even said that Village tourism transformed LGBTQ people into a consumer spectacle:

I'd say the Village attracts LGBTQ tourists and also non-LGBTQ tourists. I feel like it's one of those things that's still in tourism books and whatever as, like, "this is where the gays are. You can come see the gays in their natural habitat." (Savannah, Anglophone/Francophone, woman, queer, 22 years)

Its commodification and tourist promotion also rendered the Village "too accessible", suggesting that there was a lack of cultural capital associated with frequenting this designated LGBTQ area. Auguste, for example, implied that the Village is “... basically more men-oriented and old people go there or people from outside of Montréal who don't know the community. Well, they do know it, but it's more touristic". When asked to clarify, she said: "It's more advertised... You go a little bit further into the Mile End and Pop Montréal with all the artistic stuff ... there's another community, it's more underground" (August, Allophone, woman, lesbian, 22 years). 


\subsubsection{Queer Mile End}

Mile End is located two kilometers directly to the North of the Village. It was a twentieth-century immigrant "gateway" community and is today celebrated for the "cosmopolitanism" of its public spaces and as a centre of cultural production (Bedford 2015; Germain and Radice 2006; Rantisi and Leslie 2010). One of a few districts with a historic concentration of lesbian households, it has housed the city's few queer commercial spaces (Royal Phoenix Bar and Le Cagibi Café) and been the centre for ephemeral queer events. Thus, an LGBTQ presence in its main commercial streetscapes has never been highly visible (Fig. 13.3). About $40 \%$ of the sample lived within Mile End while another 50\% lived in the two neighbourhoods on its northern boundaries (Rosemont-Petite-Patrie and Parc-Extension) or to the East and West of the area (Le Plateau Mont-Royal and Outremont). Another 10\% lived further north in the Villeray District. While those who lived within Mile End's boundaries detailed their daily lives in the neighbourhood, all participants were asked about their perceptions and experiences of the area as well as its queer-friendly attributes. For those who lived slightly outside of its boundaries, it was the centre of their queer subcultural lives, a zone that they frequented often and where they had dense social networks.

To define the queer Mile End subculture more clearly, participants were asked to describe who was involved in its production. Their responses were extremely similar.

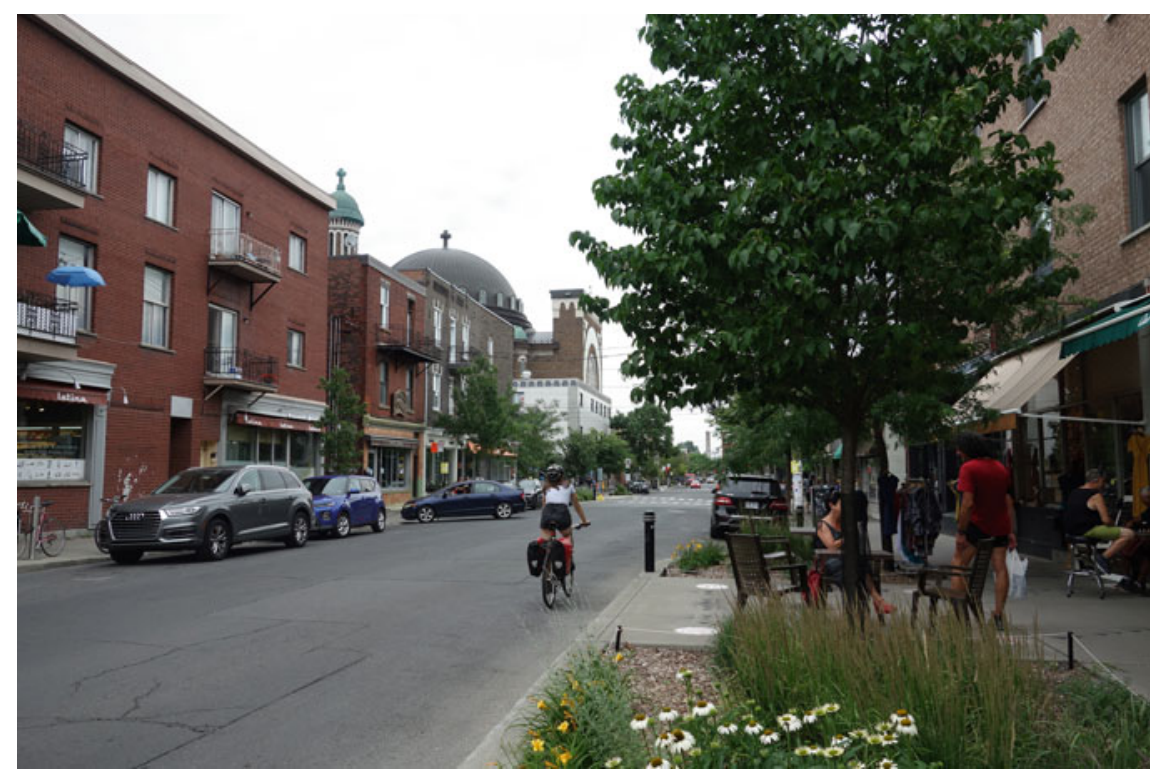

Fig. 13.3 Mile End commercial streetscape (Source Image by Author) 
First, queer Mile End was composed of young, white queers who were primarily Anglophone and middle-to-upper-middle-class. As Ève described it:

I would say that it is basically Anglophone and young. It includes a lot of trans people... It's very artsy, like students and young professionals but not entrepreneurs... So, I wouldn't say it's like high class, or rich kids, but their parents are rich, and they became queer or whatever... . (Ève, Francophone, woman, queer/lesbian, 26 years) (author's translation)

Jake also said that the queer scene in Mile End is "... very Anglo. I mean I know like a lot of Anglo quote-unquote radical queers that live in this neighbourhood" (Jake, Anglophone, transmasculine, bisexual, 26 years). He also observed that there are "... a lot of like hipster music scene queers and art queers and whatever. Like, just a very hip, Anglo, queer scene" (Jake, Anglophone, transmasculine, bisexual, 26 years). Second, like Jake, participants often spoke of the blurring of the boundaries between queer and hipster. Ashley's comments provide an example: "It's sort of like the hipster queer. It's the cool queer. I don't know. It's trendy to be queer in the Mile End" (Ashley, Allophone, woman, queer, 28 years). Thirdly, in contrast with the gay men who predominate in the Village, they said that the queer Mile End community was based in a community of queer women who were trans-inclusive. For Mer, queer Mile End is "... mostly girls, females who have a non-normative sexuality. I'm not going to call them lesbians because they wouldn't identify necessarily as that, just as queer" (Mer, Francophone, woman, queer/lesbian, 30 years). David made similar observations:

I would say that there are more queer women and I would say trans people who identify as genderqueer or as like non-gender binary in the Mile End than in the Village. There are definitely a lot of trans people in the Village, but usually people who identify differently and have access to different types of analyses about trans-ness. (David, Anglophone/Francophone, man, gay/queer, 23 years)

In summary, queer Mile End was defined as the opposite of the Village: it is young and cool, one part queer and one part hipster; it is based in a community of queer women who embrace trans-inclusion; it is predominantly Anglophone; and, according to queer Mile Enders themselves, it is populated primarily by those with high levels of education which brings elevated levels of social and cultural capital.

When asked if the Mile End is queer, most said yes, but with the caveat that it is not exclusively queer because many populations make a place for themselves in this neighbourhood. Those who replied affirmatively gave the following explanations: (1) many young queers live in Mile End; (2) it is the primary location for queer subcultural events (fundraiser parties and dances); and (3) it houses the city's only “queer” businesses (Cagibi Café and Phoenix Bar). Thus, Léo said:

I think in a general way yes, it is, because most of the queer events that I went to were located in the Mile End. And I think that those people do a lot of things in that space. There are a lot of queer-friendly spaces in the Mile End. So, I do believe in a general way that we could say that. (Léo, Allophone, man, gay, 26 years)

Sukie was more hesitant, refusing to state that the neighbourhood itself is queer. She stated, "I guess so? A lot of queer people live there. I guess it is queerish, where 
the most queer people live, ish. But, is it itself queer? I don't think so" (Sukie, Francophone, woman, gay/queer, 23 years). Many participants subscribed to this interpretation of Mile End as a shared neighbourhood that is diverse and inclusive. According to Marc:

I'd say that it's a queerer neighbourhood, but it's so much more than a queer neighbourhood. I think there's a big element of that, but I'd say it's artistic, it's inclusive, it's ethnically diverse as well more than queer, but it's queerer for sure. (Samuel, Francophone, man, gay, 26 years)

Diversity and respect for diversity_ often represented by the presence of the Hasidic Jewish community that occupies the streets in the western portion of Mile Endwas a neighbourhood characteristic valued by the participants. As the urban studies literature on gentrification suggests, Queer Mile Enders share this urban ideal with other members of the new urban middle-class in inner-city areas of the urban West (e.g. Brown-Saracino 2009; De Oliver 2016; Tissot 2014; Zukin 2008).

While ethno-cultural, socio-economic and sexual diversity signaled "inclusion" in Mile End, the presence of other overlapping alternative youth cultures was also definitive of its queer potential. Participants often pointed out that they were not the neighborhood's only youth subculture and that the boundaries between queer, hipster and creative youth subcultures was not always clear. As Dvora pointed out, the queer aesthetic has been “... adopted by non-queer people... so you can't always tell. So, like the line between queerness and hipness is like blurry..." (Dvora, Anglophone, genderqueer, queer, 23 years). Many others noted that the boundaries between hipsters and queers were blurred rendering all young people in Mile End as queer. As Nancy remarked:

I think everyone in the Mile End gets read as queer. I think it's interesting, but I also think it's a bit much. Because, you know, the hipster aesthetic, the queer aesthetic, one can always get them confused you know. So, I think people get read as queer, but maybe you don't identify that way. So, I think there's a hypervisibility that's not real. (Nancy, Allophone, woman, queer, 26 years)

Nancy described this hypervisibility as an illusion that perhaps made the Mile End appear more queer-friendly than its reality. But many participants ascribed advantages to inhabiting spaces where the boundaries between queer and non-queer young adults were fluid. Some noted that because the sexual identity of hipster men was ambiguous, their presence could evacuate the area of the hegemonic norms of masculinity that might exist elsewhere. Moreover, young hipster men, even if heterosexual, were interpreted as being always-already progressive because of their youth. According to Adrienne: "You know, I feel like people who seek the Mile End are people who want to belong to this scene that is progressive and not the old way". According to her, one aspect of this progressivism was that in the beginning "... hipster men ... they like probably looked gay" (Adrienne, Anglophone, woman, queer, 23 years). Therefore, the disruptions in mainstream masculinity signaled by the male hipster aesthetic marked Mile End as a non-heteronormative area. Participants also perceived that sexual diversity was not an issue for other people of their generation. Therefore, sharing the neighbourhood with other "progressive" young 
adults further rendered Mile End more welcoming for young queers. As an example, Archibald said that he liked it "... because Mile End is not like a defined gay neighbourhood at all, in the way that the Gay Village is a gay neighbourhood ... but there's a lot of young gay people, and just kind of very young accepting people, who aren't gay of course there" (Archibald, Anglophone, man, gay, 25 years).

At the heart of this argument is the idea that sharing space with hipsters serves to disrupt heterosexual norms and to recode the area's spaces as progressive, creative and open. This blurring of the embodied aesthetics of young populations was accompanied by a sexual indeterminacy surrounding the neighborhood's public and semipublic spaces. Jake found it difficult to distinguish between queer and hipster spaces: "It's like a bit of a hipster neighbourhood. Whether it's queer...? I think there's a lot of queer events that happen there, but I think there's like a lot of venues generally there, but whether they're like queer or not, you know?" (Jake, Anglophone, transmasculine, bisexual, 26 years). Violet said, “... what's unique about Mile End is that there's a bunch of places that are not explicitly queer but have a ton of queer staff working there that queer people feel comfortable going" (Violet, Anglophone, woman, queer, 28 years). These included bars, restaurants and cafés that were owned by queers or places she described as being, “... maybe not queer-owned, but queer-populated”. In its less visible and subtle queer presence and its patterns of integration across sexual differences, Mile End is represented as an archetypal queer-friendly neighbourhood (Gorman-Murray and Waitt 2009). Its version of LGBTQ urbanism is also distinct from that of the Village. Jaimie, for example, described her understanding of this version of urbanism: "I think that the idea of space in the Mile End for queers is more like inhabiting and not needing to necessarily identity-label yourself or like only be associating with gays or lesbians or whatever" (Jaimie, Anglophone, woman, queer, 29 years). For her, queer urbanism in Mile End was "Less rainbow flags kind of style and like being able to live more of an integrated daily life" (Jaimie, Anglophone, woman, queer, 29 years).

\subsection{Conclusion}

This chapter extends the portrait of LGBTQ neighbourhoods forming outside of gay villages and underscores the specific generational shifts that Montréal's queer Mile End represented in the early 2010s. Since that time, the neighbourhood has been evacuated of its queer subcultures and businesses as gentrification has driven them northwards into adjacent neighbourhoods. However, for a time, another form of LGBTQ urbanism emerged here that was distinctly queer within Montréal and contrasted with the territorial ideal and gender binary identities of Montréal's gay village. Primarily inhabited by Anglo young adults from middle and upper-middleclass families, the version of LGBTQ urbanism that Mile End represents is based in ideals of inclusion regarding sexual identity and more complex understandings of gender beyond sex binaries. These ideals of community and identity translate into a form of urbanism that celebrates non-commercial understandings of LGBTQ 
community, exceeding gender and sexual identity, and an overlapping with other youth subcultures laid upon the backdrop of Mile End's ethno-cultural diversity. This form of LGBTQ urbanism is distinct from with the late-twentieth century ethnic enclave as a model that territorializes LGBTQ identities and practices in gay villages (Nash 2006; Ghaziani 2019).

While unique within Montréal, queer Mile End's urbanism parallels many of the observations in the urban studies literature on the changing geographies of the queer city, but it also challenges them. Confirming Ghaziani's (2019: 12) argument that the city's many LGBTQ cultural archipelagos "exist in a productive tension with gay spaces like the gayborhood", queer Mile End is not unrelated to Montréal's gay village. Rather, distinction among queer Mile Enders is acquired through a "with-in group", class-based, generational contrast with the city's more touristic, commercial, accessible and mainstream LGBTQ space. But the example of queer Mile End also indicates that the boundaries between the two are harder than the more fluid vision Ghaziani (2019) has for the islands of the archipelago. This aspect of the production of queer identities in Mile End suggests that much more attention should be paid to the boundaries surrounding "queer-friendly" neighbourhoods. As Giraud (2012) argues, queer Mile End is much less accessible than Montréal's gay village for young people of other social classes. Social class and other factors (in this case language) create an "ambient community" signaling shared values from which to build cross-subcultural and generational commonalities beyond gender and sexuality. Queer Mile Enders ultimately felt greater affinity for other Mile End youth subcultures than they did for LGBTQ subcultures elsewhere. Following their class-based habitus, they embraced many of the principles of "hipster urbanism" (rejecting mainstream consumption, celebrating neighbourhood authenticity and cosmopolitanism, and surrounding themselves by cultural production) (Cowen 2006; Le Grand 2018; Hubbard 2016) rather than the sexual identarianism and communitarianism that once made the gay village. While not conclusive, these findings suggest that much greater attention to alternate neighbourhood formation processes is needed to capture the contemporary reshaping of the queer city after the gay village.

Acknowledgements The author would like to thank the student researchers and the participants. This research was supported by grants from Quebec's Fonds des recherche-Société et Culture (FRQSC) and Concordia University's Part-time Faculty Association (CUPFA).

\section{References}

Adriansen HK, Madsen LM (2009) Studying the making of geographical knowledge: the implications of insider interviews. Nor Geogr Tidsskr-Nor J Geogr 63(3):145-153

Atkinson R, Flint J (2001) Accessing hidden and hard-to-reach populations: snowball research strategies. Soc Res Update 33(1):93-108

Bedford W (2015) Montréal might eat its young, but Montréal won't break us down: the coproduction of place, space and independent music in Mile End, 1995-2015. J Urban Cult Stud 2(3):335-345 
Bélisle S (2011, 25 July) La communauté gaie n'est plus confinée au Village. TVA nouvelles. Available via http://tvanouvelles.ca/lcn/infos/regional/archives/2011/07/20110725-201507.html. Accessed 15 July 2015

Bitterman A, Hess DB (2016) Gay ghettoes growing gray: transformation of gay urban districts across North America reflects generational change. J America Cult 39(1):55-63

Bourdieu P (1991) Social space and symbolic space. In: Calhoun C et al (eds) Contemporary sociological theory. Wiley, Chichester, pp 325-334

Brown G (2006) Cosmopolitan camouflage: (post-)gay space in Spitalfields, East London. In: Binnie $\mathrm{J}$ et al (eds) Cosmopolitan urbanism. Routledge, London, pp 130-145

Brown M (2014) Gender and sexuality II: there goes the gayborhood? Prog Hum Geogr 38(3):457465

Browne K (2005) Snowball sampling: using social networks to research non-heterosexual women. Int J Soc Res Methodol 8(1):47-60

Brown-Saracino J (2009) A neighborhood that never changes: gentrification, social preservation, and the search for authenticity. University of Chicago Press, Chicago, IL

Brown-Saracino J (2011) From the lesbian ghetto to ambient community: the perceived costs and benefits of integration for community. Soc Probl 58(3):361-388

Collins A (2004) Sexual dissidence, enterprise and assimilation: bedfellows in urban regeneration. Urban Stud 41(9):1789-1806

Collins A, Drinkwater S (2017) Fifty shades of gay: social and technological change, urban deconcentration and niche enterprise. Urban Stud 54(3):765-785

Compton DR, Baumle AK (2012) Beyond the Castro: the role of demographics in the selection of gay and lesbian enclaves. J Homosex 59(10):1327-1356

Cowen D (2006) Hipster urbanism. Relay Soci Proj Rev 13:22-23

De Oliver M (2016) Gentrification as the appropriation of therapeutic 'diversity': a model and case study of the multicultural amenity of contemporary urban renewal. Urban Stud 53(6):1299-1316

Doan PL (2007) Queers in the American City: transgendered perceptions of urban space. Gend Place Cult 14(1):57-74

Doan PL, Higgins H(2011) The demise of queer space? Resurgent gentrification and the assimilation of LGBT neighborhoods. J Plan Educ Res 31(1):6-25

Driver S (2008) Queer youth cultures. Suny Press, Albany, NY

Duggan L (2002) The new homonormativity: the sexual politics of neoliberalism. In: Castronovo R, Nelson DD (eds) Materializing democracy: toward a revitalized cultural politics. Duke University Press, Durham, NC, pp 175-194

Forrest J, Gorman-Murray A, Siciliano F (2019) The geography of same-sex couples and families in Australia: an empirical review. Aust Geogr 50(4):493-509

Germain A, Radice M (2006) Cosmopolitanism by default: public sociability in Montréal. In: Binnie $\mathrm{J}$ et al (eds) Cosmopolitan urbanism. Routledge, London, pp 112-130

Ghaziani A (2014) There goes the gayborhood? Princeton University Press, Princeton, NY

Ghaziani A (2019) Cultural archipelagos: new directions in the study of sexuality and space. City Comm 18(1):4-22

Gieseking JJ (2016) Dyked New York: the space between geographical imagination and materialization of lesbian-queer bars and neighbourhoods. In: Brown G, Browne K (eds) The Routledge research companion to geographies of sex and sexualities. Routledge, London, pp 53-60

Giraud C (2012) Quartier gays et jeunesses homosexuelles à Paris et à Montréal. Agora débats/jeun 60(1):79-92

Giraud C (2014) Quartiers gais. Presse universitaire de France, Paris

Giraud J (2011, 13 October) Le Mile End, au cœur de la vie queer. Entre Elles. Available via http:// www.entreelles.net/2011/10/le-MileEnd-au-coeur-de-la-vie-queer-601. Accessed 15 July 2015

Goldie X (2018) Together, but separate: neighborhood-scale patterns and correlates of spatial segregation between male and female same-sex couples in Melbourne and Sydney. Urban Geogr 39(9):1391-1417 
Gorman-Murray A, Nash C (2017) Transformations in LGBT consumer landscapes and leisure spaces in the neoliberal city. Urban Stud 54(3):786-805

Gorman-Murray A, Waitt G (2009) Queer-friendly neighbourhoods: interrogating social cohesion across sexual difference in two Australian neighbourhoods. Environ Plan A 41(12):2855-2873

Halberstam J (2003) What's that smell? Queer temporalities and subcultural lives. Inter J Cultural Stud 6(3):313-333

Hayslett KL, Kane MD (2011) 'Out' in Columbus: a geospatial analysis of the neighborhood-level distribution of gay and lesbian households. City Comm 10(2):131-156

Hinrichs DW (2011) Montréal's gay village: the story of a unique urban neighborhood through the sociological lens. iUniverse, Bloomington

Hogan M (2005) Radical queers: A pop culture assessment of Montréal's anti-capitalist ass pirates, the panthères roses, and lesbians on ecstasy. Can Woman Stud 24(2):154-159

Hubbard P (2016) Hipsters on our high streets: consuming the gentrification frontier. Sociol Res Online 21(3):1-7. Available via http://www.socresonline.org.uk/21/3/1.html

Laprade B (2014) Queer in Québec: étude de la réception du mouvement queer dans les journaux québécois. Cygne noir 2. Retrieved from: http://www.revuecygnenoir.org/numero/article/queerin-quebec. Accessed 5 June 2016

Le Grand E (2018) Representing the middle-class 'hipster': emerging modes of distinction, generational oppositions and gentrification. Eur J Cult Stud. https://doi.org/10.1177/136754941877 2168

Martinez A (2015) Queer cosmopolis: the evolution of Jackson Heights. In: Doan P (ed) Planning and LGBTQ communities. Routledge, New York, NY, pp 167-180

McCarthy M (2011, 17 August) Out of the Montréal Village and into the world. XTRA! Canada's Gay and Lesbian News. Available via http://www.xtra.ca/public/National/Out_of_the_Montréal_ Village_and_into_the_world-10639.aspx. Accessed 15 July 2015

Nash CJ (2006) Toronto's gay village (1969-1982): plotting the politics of gay identity. Can Geogr $50(1): 1-16$

Nash CJ (2013a) Queering neighbourhoods: politics and practice in Toronto. ACME 12(2):193-219

Nash CJ (2013b) The age of the "post-mo"? Toronto's gay village and a new generation. Geoforum 49:243-252

Nash CJ, Gorman-Murray A (2014) LGBT neighbourhoods and 'new mobilities': towards understanding transformations in sexual and gendered urban landscapes. Int J Urban Reg Res 38(3):756-772

Plummer K (2010) Generational sexualities, subterranean traditions, and the hauntings of the sexual world: Some preliminary remarks. Symb Interact 33(2):163-191

Podmore J (2015) From contestation to incorporation: LGBT activism and urban politics in Montréal. In: Tremblay M (ed) Queer mobilizations: social movement activism and Canadian Public Policy. UBC Press, Vancouver, pp 187-207

Rantisi NM, Leslie D (2010) Materiality and creative production: the case of the mile end neighborhood in Montréal. Environ Plann A 42(12):2824-2841

Ruting B (2008) Economic transformations of gay urban spaces: revisiting Collins' evolutionary gay district model. Aust Geogr 39(3):259-269

Smart MJ, Whittemore AH (2017) There goes the gayborhood? Dispersion and clustering in a gay and lesbian real estate market in Dallas, TX, 1986-2012. Urban Stud 54(3):600-615

Spring A (2013) Declining segregation of same-sex partners: evidence from census 2000 and 2010. Popul Res Policy Rev 32(5):687-716

Tissot S (2014) Loving diversity/controlling diversity: exploring the ambivalent mobilization of upper-middle-class gentrifiers, South End, Boston. Int J Urban Reg Res 38(4):1181-1194

Wallberg D (2012, 8 March) A dash of gay and hip: Montréal's Mile End. XTRA! Canada's Gay and Lesbian News. Available via http://www.xtra.ca/public/National/TRAVEL_A_dash_ of_gay_and_hip-11659.aspx. Accessed 15 July 2015

Zukin S (2008) Consuming authenticity: from outposts of difference to means of exclusion. Cult Stud 22(5):724-748 
Julie A. Podmore is a geography professor at John Abbott College and Affiliate Assistant Professor in Geography, Planning and Environment at Concordia University. Her research on Montréal's LGBTQ communities, especially its lesbian geographies, has appeared in many collections and academic journals. Since 2016, she has been a coinvestigator of "Queering Canadian suburbs" (directed by Dr. Alison Bain, York University) which seeks to map the social, cultural and policy geographies of LGBTQ+ populations in the suburbs of Montreal, Toronto and Vancouver. She is also active in Montreal's LGBTQ+ archives community, serving on the boards of the Archives gaies du Québec and Traces: Archives lesbiennes de Québec.

Open Access This chapter is licensed under the terms of the Creative Commons Attribution 4.0 International License (http://creativecommons.org/licenses/by/4.0/), which permits use, sharing, adaptation, distribution and reproduction in any medium or format, as long as you give appropriate credit to the original author(s) and the source, provide a link to the Creative Commons license and indicate if changes were made.

The images or other third party material in this chapter are included in the chapter's Creative Commons license, unless indicated otherwise in a credit line to the material. If material is not included in the chapter's Creative Commons license and your intended use is not permitted by statutory regulation or exceeds the permitted use, you will need to obtain permission directly from the copyright holder. 